\title{
An Update on Peroneal Nerve Entrapment and Neuropathy
}

Luc M. Fortier, BA ${ }^{1}$, Michael Markel, BS ${ }^{1}$, Braden G. Thomas, BS², William F. Sherman, MD, MBA ${ }^{3}$, Bennett H. Thomas, $\mathrm{BS}^{2}$, Alan D. Kaye, MD, PhD ${ }^{4}$

\author{
1 School of Medicine, Georgetown University, ${ }^{2}$ School of Medicine, Louisiana State University Health Science Center Shreveport, ${ }^{3}$ Department of \\ Orthopaedic Surgery, Tulane University, ${ }^{4}$ Department of Anesthesiology, Louisiana State University Health Science Center Shreveport \\ Keywords: neuropathy, compression, entrapment, peroneal nerve \\ https://doi.org/10.52965/001c.24937
}

\section{Orthopedic Reviews}

Vol. 13, Issue 1, 2021

\begin{abstract}
Peroneal neuropathy is the most common compressive neuropathy of the lower extremity. It should be included in the differential diagnosis for patients presenting with foot drop, the pain of the lower extremity, or numbness of the lower extremity. Symptoms of peroneal neuropathy may occur due to compression of the common peroneal nerve (CPN), superficial peroneal nerve (SPN), or deep peroneal nerve (DPN), each with different clinical presentations. The CPN is most commonly compressed by the bony prominence of the fibula, the SPN most commonly entrapped as it exits the lateral compartment of the leg, and the DPN as it crosses underneath the extensor retinaculum. Accurate and timely diagnosis of any peroneal neuropathy is important to avoid progression of nerve injury and permanent nerve damage. The diagnosis is often made with physical exam findings of decreased strength, altered sensation, and gait abnormalities. Motor nerve conduction studies, electromyography studies, and diagnostic nerve blocks can also assist in diagnosis and prognosis. First-line treatments include removing anything that may be causing external compression, providing stability to unstable joints, and reducing inflammation. Although many peroneal nerve entrapments will resolve with observation and activity modification, surgical treatment is often required when entrapment is refractory to these conservative management strategies. Recently, additional options including microsurgical decompression and percutaneous peripheral nerve stimulation have been reported; however, large studies reporting outcomes are lacking.
\end{abstract}

\section{INTRODUCTION}

As the most common compressive neuropathy of the lower extremity, peroneal neuropathy, also known as fibular neuropathy, is a consideration for any differential diagnosis involving foot drop, the pain of the lower extremity, or numbness of the lower extremity. ${ }^{1}$ Commonly, it affects athletes and may hinder athletic performance. ${ }^{2}$ Peroneal neuropathy also affects the quality of life for those in occupations requiring significant squatting or kneeling. ${ }^{3}$ Understanding the origin, prevalence, and causes of peroneal neuropathy is imperative to holistic care for all patients experiencing lower extremity pain or weakness. This review aims to summarize the current literature on peroneal neuropathy as it pertains to epidemiology, risk factors, pathophysiology, clinical presentation, diagnosis, and treatment options.

\section{EPIDEMIOLOGY}

Peroneal neuropathy is the most common compressive neuropathy of the lower extremity. ${ }^{4}$ It is also the third most common focal neuropathy overall, after median and ulnar neuropathies. After high tibial osteotomies in conjunction with fibular osteotomies, patients reported a $2-27 \%$ incidence of peroneal neuropathy. ${ }^{1}$ Additionally, peroneal nerve palsy exists in $0.3-1.3 \%$ of those who have undergone total knee arthroplasty. ${ }^{5}$ For knee dislocations due to high energy trauma, $16-40 \%$ of patients were found to have common peroneal nerve injury. ${ }^{6}$

Children may also experience peroneal neuropathy. In a

\footnotetext{
a Corresponding Author:

Luc M. Fortier

Georgetown University School of Medicine

3900 Reservoir Road NW

Washington, DC 20007

Phone: (310) 254-6534

Lmf82@georgetown.edu
} 
case series examining 17 pediatric subjects with peroneal neuropathy, the common peroneal nerve was most often injured in children (59\%), followed by the deep (12\%) and superficial (5\%) peroneal nerves. Twenty-four percent of children in the study did not have a localizable level of injury. ${ }^{7}$ Thus, peroneal neuropathy affects all ages and is a significant cause of lower extremity weakness and pain.

\section{RISK FACTORS}

Risk factors for peroneal neuropathy are most commonly secondary to traumatic causes, followed by behavioral causes. ${ }^{1}$ Traumatic causes of peroneal neuropathy, such as knee dislocations and fibular fractures, cause direct injury to the nerve with poorer overall outcomes.

Behavioral causes such as prolonged maintenance of a crossed-leg posture or repetitive stretch from squatting may produce a peroneal nerve palsy with an acute presentation. ${ }^{3}$ Weight loss also may induce peroneal neuropathy as one case series found that $20 \%$ of 150 subjects who experienced a mean of 10.9 kilograms $(\mathrm{kg})$ of weight loss experienced peroneal nerve neuropathy. ${ }^{8}$ Bilateral peroneal mononeuropathy was seen in patients undergoing extreme weight loss, and it was also noted in $10 \%$ of World War II prisoners that had lost 5-11 kg. ${ }^{9}$

Surgeries including total knee arthroplasty, especially in the setting of a preoperative valgus knee, commonly report postoperative peroneal symptoms. Carender et al. recently performed a systematic review. They reported the incidence of common peroneal nerve injury and dysfunction after total knee arthroplasty (TKA) is $0.4 \%$ and found that $66 \%$ of cases with incomplete CPNP after TKA went on to complete recovery without surgical intervention. However, only $39 \%$ of patients with a complete CPNP after TKA had a complete recovery. ${ }^{10}$ Risk factors for postoperative palsy include the use of epidural anesthesia, preoperative valgus deformity, preoperative flexion contracture, higher body mass index, and history of diabetes mellitus. ${ }^{11-13}$ Due to the poor functional outcomes, common peroneal nerve neurolysis has been proposed as a potential treatment for CPNP after TKA with variable results warranting further study. ${ }^{14}$

Diabetes may also predispose patients to peroneal neuropathy as the deposition of sorbitol into nerves causes neural edema, leading to compression. ${ }^{15}$ High tibial and distal femoral osteotomies may also cause peroneal neuropathy by increasing the strain of the common peroneal nerve after an alignment change. Additionally, surgery positioning with stirrups and immobilization with casting or orthoses have also been documented as a cause of peroneal neuropathies. ${ }^{4}$ Mass occupying lesions, such as ganglion cysts, may also play a role in the etiology of this neurological deficit. 1

\section{PATHOPHYSIOLOGY}

The peroneal nerve arises from the L4, L5, S1, and S2 nerve roots. These nerve roots travel through the lumbosacral plexus to form the sciatic nerve. ${ }^{4}$ The sciatic nerve courses through the posterior thigh, where it branches into the tibial and common peroneal nerves. ${ }^{1}$ The common peroneal nerve then wraps around the bony prominence of the fibula, a location that is susceptible to compression. Both the deep and superficial peroneal nerves arise from the common peroneal nerve after it encounters the fibula. ${ }^{5}$ Symptoms of peroneal neuropathy may occur due to compression at the common, superficial, or deep, with slightly different clinical presentations for each.

\section{COMMON PERONEAL NERVE (CPN)}

The lateral leg compartment contains a fascial layer, known as the posterior crural intermuscular septum, deep to the peroneus longus muscle. ${ }^{15}$ This septum may compress the nerve as the CPN passes underneath to enter the lateral compartment of the leg. Such compression results in the symptoms of CPN neuropathy.

\section{SUPERFICIAL PERONEAL NERVE (SPN)}

After the division of the common peroneal nerve into the deep and superficial branches, the SPN travels in the lateral compartment of the leg. Here, it passes anteroinferior between the peroneus longus, peroneus brevis, and extensor digitorum longus muscles. Upon reaching the lower third of the leg, the SPN pierces the crural fascia to exit the lateral compartment of the leg and travels within subcutaneous fat. ${ }^{16}$ SPN entrapment most commonly occurs here as it exits the lateral compartment. ${ }^{17}$ The SPN then bifurcates into the intermediate (IDCN) and medial (MDCN) dorsal cutaneous nerves. 16

Athletes and dancers often experience compression of the SPN before it penetrates the crural fascia or at the penetration point, causing SPN mononeuropathy. Forced inversion and foot plantar flexion could lead to SPN overstretching and injury at its exiting point through the deep fascia. Recurrent stretch and inversion injuries and repetitive ankle sprains or even soft masses, like ganglia, may also induce compression nerve injury of the SPN. ${ }^{16}$ SPN mononeuropathy may also occur secondary to direct trauma, fibular fracture, tight-fitting legwear, fascial defects, or muscle herniation. ${ }^{17}$

\section{DEEP PERONEAL NERVE (DPN) - ANTERIOR TARSAL TUNNEL SYNDROME}

Anterior Tarsal Tunnel Syndrome (ATTS) is the specific name for the uncommon pathology of the DPN. The DPN becomes entrapped between the extensor retinaculum on the top of the ankle and the navicular and talus bones beneath. ${ }^{18}$ The most common cause of ATTS is trauma to the dorsum of the foot. Trauma can lead to the formation of fibrosis, adding further compression. Talonavicular osteophytosis, localized edema, high-heeled shoes, and ganglion cysts are other possible contributors to this syndrome. ${ }^{18}$

\section{CLINICAL PRESENTATION}

The clinical presentation of peroneal neuropathy varies depending on the location of nerve injury or compression. A physical exam analyzing strength, sensation, and gait can localize the specific nerves affected. 


\section{COMMON PERONEAL NERVE (CPN)}

Clinical presentation of CPN neuropathy includes weakness of ankle dorsiflexion, great toe extension, foot eversion, and sensory loss to the dorsum of the foot. The severe inability to dorsiflex and evert the foot is known as foot drop. It may result in a steppage gait, which refers to increased hip flexion of the affected extremity during the swing phase. ${ }^{15}$ Foot drop can develop acutely or gradually over the course of several weeks, varying in severity. ${ }^{19}$ Patients suffering from sensory impairments may have burning, tingling, numbness, and pain from the anterolateral aspect of the leg from just below the nerve tunnel to the dorsal aspect of the foot. ${ }^{15}$

\section{SUPERFICIAL PERONEAL NERVE (SPN)}

Superficial peroneal nerve abnormalities are rarely present in isolation. Early in the course of SPN neuropathy, there may only be symptoms during exercise. ${ }^{16}$ The SPN innervates the fibularis longus and fibularis brevis muscles and relays sensory information from the dorsum of the foot and anterolateral leg. ${ }^{17}$ Consequently, great toe extension and ankle dorsiflexion strength should be normal. However, weakness with foot eversion will likely be present. ${ }^{1}$ Decreased or abnormal sensation in the lower lateral leg, and the dorsum of the foot indicates involvement of the SPN or the portion of the sciatic nerve in those areas. ${ }^{20}$ Alternatively, there may be burning pain at the anterolateral leg and dorsum of the foot, with pressure at the entrapment point eliciting retrograde pain. Sensation deficits in the first dorsal web space and fifth toe are spared in SPN mononeuropathy. ${ }^{16}$

\section{DEEP PERONEAL NERVE (DPN) - ANTERIOR TARSAL TUNNEL SYNDROME}

DPN mononeuropathy is unique in that it may present with few symptoms or none at all. ${ }^{18}$ The DPN innervates the tibialis anterior, extensor digitorum longus, extensor hallucis longus, fibularis tertius, and extensor digitorum brevis muscles. As a result, weakness of these muscles can indicate a DPN palsy. The nerve also relays sensory information from the first web space; thus, paresthesias that radiate to the first web space may also occur. ${ }^{17,20}$ Additionally, patients with DPN neuropathy may present with anterior ankle or deep dorsal midfoot pain or dull aching that is worse with activity and shoe wear. Symptoms may be evoked with forced plantar or dorsiflexion. ${ }^{17}$

In the rare setting of a deep peroneal neuropathy in conjunction with an accessory deep fibular nerve completely innervating the extensor digitorum brevis (EDM) muscle, foot drop with preserved toe extension can be seen. ${ }^{1}$

\section{DIAGNOSIS}

Accurate and timely diagnosis of any peroneal neuropathy is essential to avoid symptoms or irreversible nerve damage progression. ${ }^{21}$ Diagnosis is made by patient history and clinical examination, which may vary depending on the location and nerve involved.

\section{COMMON PERONEAL NERVE (CPN)}

Aside from the clinical presentation of CPN neuropathy described in the previous section, the diagnosis may be aided by eliciting a Tinel's sign or performing a diagnostic nerve block. ${ }^{22}$ Motor nerve conduction studies are another helpful tool for diagnosis for localization. A recording electrode is placed over the extensor digitorum brevis, and the nerve is stimulated at three separate locations: the anterior ankle, fibular head, and popliteal fossa. ${ }^{23}$ A needle electromyography (EMG), on the other hand, is necessary to assess the severity of the injury and can guide prognosis. An EMG should examine at least the tibialis anterior, peroneus longus, and biceps femoris. However, an EMG examining other L4 to L5 and sciatic muscles can be tested in addition to differentiating a CPN mononeuropathy from sciatic neuropathy, lumbosacral plexopathy, and lumbar radiculopathy. ${ }^{23}$

For cases without a clear etiology, ultrasound offers a less expensive and non-invasive option to guide treatment. Unlike electrodiagnostic studies alone, ultrasound can detect anatomic causes such as scarring, lesions, bone fragments infiltration, and movement tethering nerves. Contralateral comparison is often helpful in determining injury. ${ }^{24}$

\section{SUPERFICIAL PERONEAL NERVE (SPN)}

SPN mononeuropathy is a relatively rare phenomenon. ${ }^{16}$ Symptoms may present similarly to CPN neuropathy, lateral leg compartment entrapment syndrome, or L5 radiculopathy, so it is important to rule these pathologies out before making a definite diagnosis.

Physical exam sensory findings sparing the dorsum of the first web space and motor findings sparing weakness of great toe extension and ankle dorsiflexion can assist in the localization of CPN entrapment. Patients with muscle herniation or a fascial defect may also display a mass or swelling at the site of insult that worsens with use. An injection of anesthetic to the area of suspicion with relief of symptoms can confirm a suspected diagnosis. ${ }^{25}$

\section{DEEP PERONEAL NERVE (DPN)}

Radiographic imaging is important for diagnosing DPN neuropathy specifically as the most common causes are secondary to nerve impingement by osteophytes and trauma. ${ }^{17}$ Furthermore, symptoms of DPN neuropathy may be evoked with forced plantar or dorsiflexion and/or a positive Tinel sign over the site of entrapment. The precise site of compression can also be located by a nerve block of the affected area. $^{25}$

\section{CONSERVATIVE TREATMENT}

Treatment of peroneal nerve injuries varies based on the etiology and severity of symptoms. When left untreated, peroneal nerve palsy can progress to foot drop, limb disability, and eventually limb deformity. However, partial or full function often resolves over time, so initial treatment of a peroneal nerve palsy is nonsurgical with bracing and 
observation. These initial non-invasive treatment options include lifestyle modification and changes in activities that trigger neuropathy. ${ }^{19}$

The most common and effective nonsurgical treatment options for CPN have been physical therapy maneuvers with nerve gliding and nerve flossing. ${ }^{21}$ Padding of the fibular head is another indirect trauma injury option and can work at night to prevent compression while sleeping. ${ }^{19}$

Management of an SPN palsy should be tailored to the etiology. Conservative initial treatment is indicated, including physical therapy, appropriate footwear, limited injections, and rehabilitation for ankle instability. ${ }^{17}$ For injuries that include muscle weakness, strengthening of the dorsiflexors and evertors is indicated. If the muscle weakness is severe, electrical stimulation can assist in the contraction of the weakened muscles. ${ }^{19}$ Orthotic intervention is another option for isolated SPN neuropathies and includes a lateral wedge shoe insert to decrease supination of the foot. Ankle foot orthosis is also indicated for DPN neuropathy and ankle dorsiflexor weakness. ${ }^{26}$

An alternative treatment to consider before surgical intervention includes hydrodissection. ${ }^{27}$ Treatment involves injecting a nonirritating solution around the nerve to reduce the pressure from surrounding structures. These solutions include saline, anesthetics, steroids, plasma, and dextrose. The main functions of this treatment are to release soft tissue adhesions that cause entrapment and restore the nerve's function. Hydrodissection has been used in conjunction with ultrasound to guide the placement of the injection. ${ }^{27}$

\section{MINIMALLY INVASIVE TREATMENT}

A less invasive option for CPN surgical treatment was recently described by Morimoto et al., in which 33 legs were treated with microsurgical decompression under local anesthesia. ${ }^{28}$ No sedatives were used during the procedure so that symptom improvement could be monitored intraoperatively. Upon decompression with dissection of the fibrous band between the superficial head of the peroneus longus and soleus, all 22 patients reported symptom relief. There were no reported postoperative complications or symptom recurrence during the mean postoperative follow-up period of 40 months. ${ }^{28}$

The superficial course of the SPN $<1 \mathrm{~cm}$ deep to the dermis makes it particularly susceptible to injury and compression; nonetheless, it also makes it a candidate for peripheral nerve stimulation (PNS). ${ }^{29}$ Consequently, percutaneous PNS is an alternative minimally invasive treatment method for certain pain manifestations of peroneal neuropathy. A common target for SPN lead placement is in the distal leg, just proximal to the lateral malleolus. With ultrasound guidance for lead implantation, nerve leads may be placed more accurately, resulting in increased pain relief using percutaneous PNS. Although large studies reporting outcomes from treatment with this modality are lacking, the development of new percutaneous PNS systems and the use of ultrasound for lead implantation have rapidly expanded and offered a potential treatment option. ${ }^{29}$

\section{SURGICAL TREATMENT}

\section{COMMON PERONEAL NERVE}

When CPN entrapment is either refractory to nonsurgical treatment options or causes a severe reduction in conduction such as a secondary mass effect or laceration, surgical decompression or repair is the mainstay treatment option. ${ }^{30} \mathrm{CPN}$ decompression has been shown to rapidly and significantly improve drop foot and increase ankle stability in those suffering from entrapment. ${ }^{31}$ Decompression is typically performed under a microscope by carefully transecting the two layers of fascia surrounding the nerve proximally and distally to the fibular neck, where CPN injury most commonly occurs. ${ }^{2,31-33}$

In a prospective study consisting of 15 patients with CPN entrapment, 14 patients underwent surgical decompression after the failure of medical management. ${ }^{32}$ of the 14 patients who underwent surgical decompression, 13 improved motor function immediately after surgery and at 1,6 , and 12 months postoperatively. At the same time, 7 also reported full recovery of motor function at 12 months postoperatively. ${ }^{32}$ A retrospective review of a prospective database of patients with CPN palsy due to various etiologies showed clinical improvement in 28 of 30 patients who underwent neuroplasty and decompression. ${ }^{33}$ Another study that reviewed subjects with CPN compression and foot drop secondary to weight loss showed an $85 \%$ success rate in patients receiving external neurolysis at the fibular head. ${ }^{34} \mathrm{~A}$ recent retrospective analysis of 35 patients undergoing microneurolysis and nerve decompression resulted in only 1 poor outcome, indicated by the inability to dorsiflex the ankle to 90 degrees. ${ }^{35}$ Overall, surgical decompression effectively treats CPN entrapment, with some studies showing a positive correlation between decreased time to surgery and improved outcomes. ${ }^{32}$

\section{SUPERFICIAL PERONEAL NERVE}

SPN entrapment is less common than CPN entrapment, and studies show that most patients who undergo decompressive surgery for SPN entrapment have previously undergone surgery for CPN entrapment. ${ }^{36}$ SPN entrapment is a commonly missed diagnosis; therefore, surgeons working distally to the knee must be aware of the technical maneuvers and be familiar with the anatomy of the peripheral nerves in the lower extremity. ${ }^{37}$ Decompression of the SPN is performed where the nerve exits the lateral compartment and should extend to include its terminal nerve branches. ${ }^{2,38}$

A small study of 5 patients, previously treated with surgical decompression of CPN entrapment, all showed improvement of symptoms immediately after SPN surgical decompression. ${ }^{36}$ Of these 5 patients, entrapment symptoms recurred in one patient who required additional complete nerve decompression with no further return of symptoms. ${ }^{36}$ A more extensive study of 54 patients undergoing SPN decompression showed $69 \%$ of subjects reported some improvement in the effect of pain on quality of life, with a positive correlation between pain severity and improvement with surgery. ${ }^{39}$ An additional study reported an $85 \%$ success rate with SPN nerve decompression. ${ }^{38}$ The authors note that failure of surgical decompression in those with chronic 
nerve pain may be secondary to the centralization of pain over time. ${ }^{38}$ In these cases, pain management specialists and biopsychologists are recommended to improve the success of surgical decompression. ${ }^{38}$

\section{DEEP PERONEAL NERVE}

Compression of the DPN, known as ATTS, can be surgically treated with either an open or arthroscopic approach. 40 Surgical approach involves an incision in the dorsum of the foot and releasing the nerve from the inferior extensor retinaculum to its entry into the deep fascia. It is also essential to remove any associated osteophytes. ${ }^{41}$ In a study of 13 patients who underwent surgical decompression of the DPN, 6 underwent an endoscopic procedure, and 7 underwent an open procedure. ${ }^{40}$ Twelve of the 13 patients reported significant improvement in condition, with no complications. ${ }^{40}$ Another study of 18 patients undergoing surgical release of the DPN reported excellent results in $60 \%$ and good results in $20 \%$, while only $20 \%$ of patients showed no improvement. ${ }^{42}$ An additional study of 7 patients showed immediate and lasting pain relief in 6 cases following surgical DPN release, with recurrence of symptoms and secondary surgery in one case. ${ }^{41}$

\section{CASE REPORTS}

\section{COMMON PERONEAL NERVE}

Many case reports of CPN entrapment are described in the literature and are associated with many etiologies and treatment regimens. CPN compression secondary to a cystic tibiofibular joint was reported in various cases. ${ }^{41,43-45}$ Two such cases described CPN compression due to intraneural ganglion and synovial cysts. ${ }^{41,45}$ Complete return of motor function was accomplished via cyst aspiration in one case, while the other was treated with prompt surgical cyst removal and nerve decompression. ${ }^{43,44}$ Two other reports of cystic etiologies included an extraneural popliteal cyst and two cases of children with extraneural tibiofibular joint synovial cysts, all of which were treated with surgical cyst removal and CPN decompression. ${ }^{45,46}$

CPN compression due to bony growths were also commonly reported in multiple case reports. ${ }^{47-50}$ Two cases involved osteochondromas of the fibular head causing CPN entrapment, both of which achieved symptom resolution with tumor excision. ${ }^{48,50}$ Rarer cases of bony overgrowth include melorheostosis, a bone hyperostosis disorder, and a fabella, a sesamoid bone in the posterolateral knee, causing $\mathrm{CPN}$ compression that required treatment with surgical removal of the bony lesions. ${ }^{47,49}$

Some cases of CPN entrapment secondary to muscular etiologies include a cadaver with an unusual anatomical variant of the distal biceps femoris and a diabetic patient who presented with peroneal muscle infarction treated with a splint and diabetic control. ${ }^{51,52}$ Two cases detailed prolonged squatting as a source of CPN compression, in which one case was due to hemorrhoids and another due to working on sewer pipes. ${ }^{53,54}$ The case of the sewer worker resolved primarily with rest, while the patient with hemorrhoids required physical therapy and external devices. ${ }^{53,54}$ A rare case of a CPN schwannoma in a young patient was also reported and treated with simple surgical resection of the lesion. 55

\section{SUPERFICIAL PERONEAL NERVE}

Case reports of SPN entrapment are similar to CPN entrapment in presentation, diagnosis, and treatment. Multiple cases involved muscle herniation leading to SPN compression; 12 cases of peroneus brevis herniation, and one of tibialis anterior herniation, all of which were treated with surgical nerve decompression via fasciotomy. ${ }^{56-58}$ Another case reported nerve entrapment due to herniation, but in this case, the SPN herniated with the peroneal muscles through a fascial tear, requiring surgical fasciotomy to release the intrafascial septum. ${ }^{59}$

SPN compression due to ganglion cysts were seen in a case report of a young female dancer, requiring surgical cyst removal and nerve decompression to enable the patient to return to dancing. ${ }^{60}$ Another case report described entrapment due to an SPN schwannoma, in which surgical removal of the schwannoma resulted in symptom resolution. One unusual etiology of SPN entrapment was reported in a patient with a distal fibular fracture following a closed reduction. ${ }^{61}$ The nerve became trapped within the bony fragments of the fracture site during reduction, which required surgical decompression of the nerve and internal fixation of the fracture. ${ }^{61}$

\section{DEEP PERONEAL NERVE}

Fewer case reports are detailing DPN entrapment, with a total of three identified. In these cases, DPN entrapment was due to ganglion cysts in 2 cases and bony overgrowth of the navicular bone in 1 case. ${ }^{62-64}$ One of the ganglion cysts was treated with CT-guided fenestration, pulsed radiofrequency modulation, and steroid injection into the cyst. In contrast, the other ganglion cyst case was treated with ultrasoundguided aspiration. Both patients reported successful nerve decompression and return of motor function. ${ }^{62,64}$ The case of DPN entrapment due to navicular bone overgrowth was treated successfully with surgical nerve decompression. ${ }^{63}$

\section{CONCLUSION}

While entrapment neuropathies are relatively uncommon in the lower extremities, peroneal nerve entrapment is the most frequently encountered lower limb neuropathy. 1,65 Due to the relative infrequency of lower limb neuropathies, diagnosis can be difficult and often overlooked. ${ }^{65}$ Providers must have a level of suspicion when patients present with chronic leg pain, foot drop, or ankle instability that has not responded to conservative medical management. ${ }^{65}$ Peroneal nerve entrapment is most commonly at or around the fibular head but can also occur in the calf, ankle, or foot. ${ }^{1}$ Electrodiagnostic studies have shown to be helpful in the diagnosis of nerve entrapment and in determining the type of injury and the level at which the entrapment occurs. ${ }^{1}$ First-line treatment usually includes removing anything that may be causing external compression, providing stability to any unstable joints that may be putting tension on the nerve, and reducing inflammation. ${ }^{65}$ Although many 
peroneal nerve entrapments will resolve with less invasive treatment. Surgical treatment is often required when entrapment is refractory to conservative management. ${ }^{30}$ Surgical treatment involves neurolysis via release of the overlying facial planes and should be tailored to address the entrapment's etiology and the specific location. ${ }^{65}$ Surgical decompression reported positive outcomes in the cases we studied, with most studies showing improvement in at least $80 \%$ of patients who underwent surgical decompression. ${ }^{32-36,38}$ Overall, a diagnosis of peroneal nerve entrapment is associated with a good prognosis, in which most patients experience a full return of nerve function after nec- essary treatment, whether that be conservative management or surgery.

\section{CONFLICTS OF INTEREST}

No conflict of interests to disclose.

Submitted: June 01, 2021 EST, Accepted: June 16, 2021 EST 


\section{REFERENCES}

1. Marciniak C. Fibular (Peroneal) Neuropathy. Electrodiagnostic Features and Clinical Correlates. Phys Med Rehabil Clin N Am. Published online 2013. $\underline{\mathrm{d}}$ oi:10.1016/i.pmr.2012.08.016

2. Meadows JR, Finnoff JT. Lower extremity nerve entrapments in athletes. Curr Sports Med Rep. Published online 2014. doi:10.1249/ISR.00000000000 $\underline{00083}$

3. Bonfiglioli R, Mattioli S, Violante FS. Occupational mononeuropathies in industry. In: Handbook of Clinical Neurology. Vol 131. Elsevier B.V.; 2015:411-426. doi:10.1016/B978-0-444-62627-1.0002 $\underline{1-4}$

4. Bowley MP, Doughty CT. Entrapment Neuropathies of the Lower Extremity. Med Clin North Am. 2019;103(2):371-382. doi:10.1016/i.mcna.2018.10.013

5. Bouche P. Compression and entrapment neuropathies. In: Handbook of Clinical Neurology. Vol 115. Elsevier B.V.; 2013:311-366. doi:10.1016/B97 8-0-444-52902-2.00019-9

6. Moatshe G, Dornan GJ, Løken S, Ludvigsen TC, Laprade RF, Engebretsen L. Demographics and injuries associated with knee dislocation: A prospective review of 303 patients. Orthop J Sport Med. 2017;5(5). doi:10.1177/2325967117706521

7. Jones HR, Felice KJ, Gross PT. Pediatric peroneal mononeuropathy: A clinical and electromyographic study. Muscle Nerve. 1993;16(11):1167-1173. doi:10.1 $\underline{002 / \text { mus.880161105 }}$

8. Cruz-Martinez A, Arpa J, Palau F. Peroneal neuropathy after weight loss. J Peripher Nerv Syst. 2000;5(2):101-105. doi:10.1046/j.1529-8027.2000.000 07.

9. Margulis M, Ben Zvi L, Bernfeld B. Bilateral Common Peroneal Nerve Entrapment After Excessive Weight Loss: Case Report and Review of the Literature. J Foot Ankle Surg. 2018;57(3):632-634. do i:10.1053/i.jfas.2017.10.035

10. Carender CN, Bedard NA, An Q, Brown TS. Common Peroneal Nerve Injury and Recovery after Total Knee Arthroplasty: A Systematic Review. Arthroplast Today. 2020;6(4):662-667. doi:10.1016/j.ar td.2020.07.017
11. Idusuyi OB, Morrey BF. Peroneal nerve palsy after total knee arthroplasty: Assessment of predisposing and prognostic factors. J Bone Jt Surg - Ser A. 1996;78(2):177-184. doi:10.2106/00004623-19960200 $\underline{0-00003}$

12. Beller J, Trockel U, Lukoschek M.

Peronäusläsionen nach KTEP-implantation unter verwendung einer postoperativ fortgeführten periduralen analgesie. Orthopade. 2008;37(5):475-480. doi:10.1007/s00132-008-1257-x

13. Park JH, Restrepo C, Norton R, Mandel S, Sharkey $\mathrm{PF}$, Parvizi J. Common peroneal nerve palsy following total knee arthroplasty: Prognostic factors and course of recovery. J Arthroplasty. 2013;28(9):1538-1542. oㅡ i:10.1016/i.arth.2013.02.025

14. Zywiel MG, Mont MA, McGrath MS, Ulrich SD, Bonutti PM, Bhave A. Peroneal Nerve Dysfunction After Total Knee Arthroplasty. Characterization and Treatment. J Arthroplasty. 2011;26(3):379-385. doi:1 0.1016/j.arth.2010.03.020

15. Anderson JC. Common Fibular Nerve Compression Anatomy, Symptoms, Clinical Evaluation, and Surgical Decompression. Clin Podiatr Med Surg. 2016;33(2):283-291. doi:10.1016/i.cpm.2015.12.005

16. Tzika M, Paraskevas G, Natsis K. Entrapment of the superficial peroneal nerve: An anatomical insight. J Am Podiatr Med Assoc. 2015;105(2):150-159. doi:1 0.7547/0003-0538-105.2.150

17. Meadows JR, Finnoff JT. Lower extremity nerve entrapments in athletes. Curr Sports Med Rep. 2014;13(5):299-306. doi:10.1249/ISR.0000000000000 $\underline{083}$

18. Logullo F, Ganino C, Lupidi F, Perozzi C, Di Bella P, Provinciali L. Anterior tarsal tunnel syndrome: A misunderstood and a misleading entrapment neuropathy. Neurol Sci. 2014;35(5):773-775. doi:10.10 07/s10072-013-1601-8

19. Garg B. Peroneal Nerve Palsy: Evaluation and Management. J Am Acad Orthop Surg. 2016;24(5):e49. doi:10.5435/JAAOS-D-16-00045

20. Poage C, Roth C, Scott B. Peroneal Nerve Palsy. J Am Acad Orthop Surg. 2016;24(1):1-10. doi:10.5435/I AAOS-D-14-00420 
21. Bregman PJ, Schuenke MJ. A Commentary on the Diagnosis and Treatment of Superficial Peroneal (Fibular) Nerve Injury and Entrapment. J Foot Ankle Surg. 2016;55(3):668-674. doi:10.1053/j.jfas.2015.11.0 $\underline{05}$

22. Nirenberg MS. A simple test to assist with the diagnosis of common fibular nerve entrapment and predict outcomes of surgical decompression. Acta Neurochir. 2020;162(6):1439-1444. doi:10.1007/s0070 1-020-04344-3

23. Hobson-Webb LD, Juel VC. Common Entrapment Neuropathies. Contin Lifelong Learn Neurol. 2017;23(2):487-511. doi:10.1212/CON.000000000000 $\underline{0452}$

24. Bignotti B, Assini A, Signori A, Martinoli C, Tagliafico A. Ultrasound versus MRI in common fibular neuropathy. Muscle and Nerve. 2017;55(6):849-857. doi:10.1002/mus.25418

25. Pomeroy G, Wilton J, Anthony S. Entrapment Neuropathy About the Foot \& Ankle. J Am Acad Orthop Surg Copyr. 2015;23:58-66.

26. Bianchi S, Droz L, Le Corroller T, Delmi M. Partial anterior tunnel syndrome: a retrospective analysis of ultrasound findings in four surgically proven cases. Skeletal Radiol. 2019;48(5):807-812. doi:10.1007/s002 56-018-3056-8

27. Song B, Marathe A, Chi B, Jayaram P. Hydrodissection as a therapeutic and diagnostic modality in treating peroneal nerve compression. Baylor Univ Med Cent Proc. 2020;33(3):465-466. doi:1 0.1080/08998280.2020.1758006

28. Morimoto D, Isu T, Kim K, et al. Microsurgical decompression for peroneal nerve entrapment neuropathy. Neurol Med Chir. 2015;55(8):669-673. do i:10.2176/nmc.oa.2014-0454

29. Hanyu-Deutmeyer A, Pritzlaff SG. Peripheral Nerve Stimulation for the 21st Century: Sural, Superficial Peroneal, and Tibial Nerves. Pain Med. 2020;21(Supplement_1):S64-S67. doi:10.1093/pm/pna a202

30. Poage C, Roth C, Scott B. Peroneal Nerve Palsy: Evaluation and Management. J Am Acad Orthop Surg. Published online 2016. doi:10.5435/JAAOS-D-14-004 $\underline{20}$

31. Anderson JC. Common Fibular Nerve Compression. Clin Podiatr Med Surg. Published online 2016. doi:10.1016/i.cpm.2015.12.005
32. Tarabay B, Abdallah Y, Kobaiter-Maarrawi S, Yammine P, Maarrawi J. Outcome and Prognosis of Microsurgical Decompression in Idiopathic Severe Common Fibular Nerve Entrapment: Prospective Clinical Study. World Neurosurg. Published online 2019. doi:10.1016/j.wneu.2019.02.042

33. Souter J, Swong K, McCoyd M, Balasubramanian N, Nielsen M, Prabhu VC. Surgical Results of Common Peroneal Nerve Neuroplasty at Lateral Fibular Neck. World Neurosurg. Published online 2018. doi:10.1016/ j.wneu.2018.01.061

34. Broekx S, Weyns F. External neurolysis as a treatment for foot drop secondary to weight loss: a retrospective analysis of 200 cases. Acta Neurochir. Published online 2018. doi:10.1007/s00701-018-361 $\underline{4-9}$

35. Terzis JK, Kostas I. Outcomes with microsurgery of common peroneal nerve lesions. J Plast Reconstr Aesthetic Surg. Published online 2020. doi:10.1016/j.bj ps.2019.02.031

36. Matsumoto J, Isu T, Kim K, Iwamoto N, Yamazaki $\mathrm{K}$, Isobe $\mathrm{M}$. Clinical features and surgical treatment of superficial peroneal nerve entrapment neuropathy. Neurol Med Chir. Published online 2018. doi:10.2176/ nmc.oa.2018-0039

37. Bregman PJ, Schuenke MJ. A Commentary on the Diagnosis and Treatment of Superficial Peroneal (Fibular) Nerve Injury and Entrapment. J Foot Ankle Surg. Published online 2016. doi:10.1053/i.jfas.2015.1 1.005

38. Bregman PJ, Schuenke M. Current Diagnosis and Treatment of Superficial Fibular Nerve Injuries and Entrapment. Clin Podiatr Med Surg. Published online 2016. doi:10.1016/i.cpm.2015.12.007

39. Franco MJ, Phillips BZ, Lalchandani GR, Mackinnon SE. Decompression of the superficial peroneal nerve: Clinical outcomes and anatomical study. J Neurosurg. Published online 2017. doi:10.317 1/2016.1.JNS152454

40. Yassin M, Garti A, Weissbrot M, Heller E, Robinson D. Treatment of anterior tarsal tunnel syndrome through an endoscopic or open technique. Foot. Published online 2015. doi:10.1016/j.foot.2015.0 $\underline{5.007}$

41. Dhinsa BS, Hussain L, Singh S. The management of dorsal peroneal nerve compression in the midfoot. Foot. Published online 2018. doi:10.1016/i.foot.2017.1 $\underline{2.005}$

42. Ferkel E, Davis WH, Ellington JK. Entrapment Neuropathies of the Foot and Ankle. Clin Sports Med. Published online 2015. doi:10.1016/i.csm.2015.06.002 
43. Reisch T, Helmy N, Antoniadis A. Acute Motor Failure of the NPeroneus Profundus Caused by a Cystic Tibiofibular Joint. Z Orthop Unfall. Published online 2019. doi:10.1055/a-0790-8542

44. Park SH, Do HK, Jo GY. Compressive peroneal neuropathy by an intraneural ganglion cyst combined with L5 radiculopathy: A case report. Medicine. Published online 2019. doi:10.1097/MD.00000000000 $\underline{17865}$

45. Zeng X, Xie L, Qiu Z, Sun K. Compression neuropathy of common peroneal nerve caused by a popliteal cyst: A case report. Med. Published online 2018. doi:10.1097/MD.0000000000009922

46. Robin F, Kuchenbuch M, Sauleau P, et al. Paralysie du nerf fibulaire commun: Diagnostic rare chez l'enfant d'un kyste synovial tibio-fibulaire supérieur. Arch Pediatr. Published online 2016. doi:10.1016/j.arc ped.2015.10.005

47. Puffer RC, Sabbag OD, Logli AL, Spinner RJ, Rose PS. Melorheostosis Causing Compression of Common Peroneal Nerve at Fibular Tunnel. World Neurosurg. Published online 2019. doi:10.1016/j.wneu.2019.04.20 $\underline{8}$

48. Argyriou C, Drosos G, Tottas S, Tasopoulou KM, Kougioumtzis I, Georgiadis GS. A Rare Case of Tibioperoneal Arterial Trunk Entrapment Caused by a Fibular Osteochondroma. Ann Vasc Surg. Published online 2019. doi:10.1016/i.avsg.2018.06.024

49. Cesmebasi A, Spinner RJ, Smith J, Bannar SM, Finnoff JT. Role of sonography in the diagnosis and treatment of common peroneal neuropathy secondary to fabellae. J Ultrasound Med. Published online 2016. doi:10.7863/ultra.15.04003

50. Gökkuș K, Atmaca H, Sağtaș E, Saylik M, Aydin AT. Osteochondromas originating from unusual locations complicating orthopedic discipline: Case series. Eklem Hast ve Cerrahisi. Published online 2015. doi:10.5606/ ehc. 2015.21

51. Desmottes MC, Brehier Q, Bertolini E, Monteiro I, Terreaux W. Compression of the common peroneal nerve due to peroneal muscle infarction in a patient with diabetes. Jt Bone Spine. Published online 2019. $\underline{\mathrm{d}}$ oi:10.1016/j.jbspin.2018.05.012

52. Park JH, Park KR, Yang J, Park GH, Cho J. Unusual variant of distal biceps femoris muscle associated with common peroneal entrapment neuropathy: A cadaveric case report. Med. Published online 2018. do $\mathrm{i}: 10.1097 / \mathrm{MD} .0000000000012274$
53. Koksal A, Dogan VB. Acute bilateral drop foot as a complication of prolonged squatting due to haemorrhoid. Ideggyogy Sz. Published online 2019. do i:10.18071/isz.72.0353

54. Kodaira M, Sekijima Y, Ohashi N, et al. Squattinginduced bilateral peroneal nerve palsy in a sewer pipe worker. Occup Med. Published online 2017. doi:10.109 3/occmed/kqw133

55. Van Zantvoort APM, Cuppen P, Scheltinga MR. Management and patients perspective regarding a common peroneal nerve schwannoma: A rare cause of lower leg pain in a young individual. BMJ Case Rep. Published online 2017. doi:10.1136/bcr-2017-220704

56. Paolasso I, Cambise C, Coraci D, et al. Tibialis anterior muscle herniation with superficial peroneal nerve involvement: Ultrasound role for diagnosis and treatment. Clin Neurol Neurosurg. Published online 2016. doi:10.1016/j.clineuro.2016.09.019

57. Foresti M. Superficial peroneal nerve compression due to peroneus brevis muscle herniation. J Radiol Case Rep. Published online 2019. doi:10.3941/ircr.v13i $\underline{11.3757}$

58. Tong O, Bieri P, Herskovitz S. Nerve entrapments related to muscle herniation. Muscle and Nerve. Published online 2019. doi:10.1002/mus.26643

59. Haddad SF, Harrington M, Adams C, Arain A, Czajka C. Acute Superficial Peroneal Nerve Entrapment Mimicking Compartment Syndrome: A Case Report. JBJS Case Connect. Published online 2019. doi:10.2106/JBJS.CC.19.00137

60. Martin D, Dowling J, Rowan F, Casey M, O’Grady P. Superficial peroneal nerve paresis in a dancer caused by a midfoot ganglion: case report. J Dance Med Sci. Published online 2015. doi:10.12678/1089-313X.1 9.2.77

61. Corey RM, Salazar DH. Entrapment of the Superficial Peroneal Nerve Following a Distal Fibula Fracture. Foot Ankle Spec. Published online 2017. do i: $10.1177 / 1938640016640887$

62. Brestas P, Protopsaltis I, Drossos C. Role of sonography in the diagnosis and treatment of a ganglion cyst compressing the lateral branch of deep peroneal nerve. J Clin Ultrasound. Published online 2017. doi:10.1002/jcu.22388

63. Milants C, Wang FC, Gomulinski L, et al. Le syndrome tarsien antérieur. Rev Med Liege. Published online 2015 .

64. Alsahhaf A, Renno WM. Ganglion cyst at the proximal tibiofibular joint in a patient with painless foot drop. Pain Physician. Published online 2016. 
65. Pomeroy G, Wilton J, Anthony S. Entrapment neuropathy about the foot and ankle: An update. J Am Acad Orthop Surg. Published online 2015. doi:10.543 5/JAAOS-23-01-58 